\title{
Constraints Faced by Potato Growers Involved in Potato Cultivation Activities
}

\author{
Katayani $^{1}$, Dr. Nimisha Awasthi ${ }^{2}$, Dr. Ritu Pandey ${ }^{3}$, Dr. Kirtima Sachan ${ }^{4}$ \\ ${ }^{1,4} \mathrm{Ph} . D$ Scholar, Department of FRM, MAB College of Home Science, C.S.A.U.A. \& T., Kanpur \\ ${ }^{2}$ Programme Assistant, Department of FRM, MAB College of Home Science, C.S.A.U.A. \& T., Kanpur \\ ${ }^{3}$ Assistant Professor, Department of FRM, MAB College of Home Science, C.S.A.U.A. \& T., Kanpur
}

\begin{abstract}
Potato is the leading vegetable crop in the world which occupy the top most position after rice and wheat in respect of production and consumption. In spite of this potato growers faced so many problems that affect production, marketing and consumption, therefore they want to either shift or leave the agriculture profession. Present study entitled "Constraints Faced by Potato Growers Involved in Potato Cultivation Activities" The pre-coded interview schedule was constructed in order to elicit information needed to obtain the objectives of the study. Multistage purposive random sampling technique was followed to select the state, district, blocks and finally respondents. District Kannauj is purposively selected as this is one of the largest potato producer districts while two blocks namely Kannauj and Jalabad were randomly selected. Two villages from each selected block i.e. Basirapur and Mahmoadpur paith from Kannauj and, Badlepurwa and Kheda from Jalalabad, selected randomly. Forty farmers from each selected village, Total sample size 160 respondents were randomly selected for final data collection. More than fifty percent respondents „Always" suffered with problem of ,fluctuation of price" and, therefore, this constraint was identified as Rank I. Major constraints „Always" faced by maximum respondents were „Unovailability of cold storage" and „lack of potato processing unit" and thus identified Rank II and Rank III. Untimely "wage payment" and "no employment in odd season" were identified least faced constraints with Rank XIV and Rank XV respectively.
\end{abstract}

Keywords: Potato Growers, Constrains, Potato Cultivation activities

\section{Introduction}

Potato is one of the four major food crops of the world. The other three crops being rice, wheat and maize. The global area under potato during 1998 was about 18 million ha with a total production of about 295 million tonnes. U.P. is the major potato growing state in India followed by West Bengal and Bihar with the production of 10455.30, 7482.30 and 1720.20 thousand tones, respectively. The highest productivity of the crop is inWest Bengal followed by Gujrat. In respect to Uttar Pradesh, Kannouj district is the highest producer of potato followed by Farrukhabad and Agra with the production of 942299,832744 and 647025 metric tonnes and area being 34595,29793and 18156 hectares, respectively. . But in average productivity (q./ha) district Agra having 1 place (356.37) followed by Mathura (339.37 q/ha) and Rampur (336.49 q/ha). (U.P ke pramukh krishi ankare.Directorate of Agriculture, Lucknow, 20012002).

\section{Research Methodology}

The study was conducted in Kannauj district of Uttar Pradesh during the year 2015. The pre-coded interview schedule was constructed in order to elicit information needed to obtain the objectives of the study. Multistage purposive random sampling technique was followed to select the state, district, blocks and finally respondents. District Kannauj is purposively selected as this is one of the largest potato producer districts while two blocks namely Kannauj and Jalabad were randomly selected. Two villages from each selected block i.e. Basirapur and Mahmoadpur paith from Kannauj and, Badlepurwa and Kheda from Jalalabad, selected randomly. Forty farmers from each selected village, Total sample size 160 respondents were randomly selected for final data collection.

\section{Result and Discussion}

Table 1: Mean Distribution of Potato Growers on the Basis of Constraints Faced $\mathrm{N}=160$

\begin{tabular}{|c|c|c|c|c|c|c|}
\hline S. No. & Constraints & Always & Some times & Never & Mean Score & Rank \\
\hline 1 & Unavailability of labour & $65(40.62)$ & $64(40.00)$ & $31(19.37)$ & 02.21 & VI \\
\hline 2 & High cost of input for potato cultivation & $34(21.25)$ & $70(43.75)$ & $56(35.00)$ & 01.86 & XII \\
\hline 3 & Gap in storage of labours during season & $79(42.50)$ & $13(8.12)$ & $68(42.50)$ & 02.06 & VIII \\
\hline 4 & Untimely wage payment & $22(13.75)$ & $52(32.50)$ & $86(53.75)$ & 01.60 & XIV \\
\hline 5 & No employment in odd season & $8(05.00)$ & $62(38.75)$ & $90(56.25)$ & 01.48 & $\mathrm{XV}$ \\
\hline 6 & Lack of availability of sufficient good quality seed & $91(56.87)$ & $20(12.50)$ & $49(30.62)$ & 02.26 & $\mathrm{~V}$ \\
\hline 7 & Enough fertilizer not available in time & $61(38.12)$ & $61(38.12)$ & $38(23.75)$ & 02.14 & VII \\
\hline 8 & Low cost transport system & $41(25.62)$ & $61(38.12)$ & $58(36.25)$ & 01.89 & $\mathrm{XI}$ \\
\hline 9 & High charges of cold storage & $79(49.37)$ & $36(22.50)$ & $45(28.12)$ & 02.21 & VI \\
\hline 10 & Unavailability of cold storage & $71(44.37)$ & $78(48.75)$ & $11(06.87)$ & 02.37 & II \\
\hline
\end{tabular}




\section{International Journal of Science and Research (IJSR) \\ ISSN (Online): 2319-7064}

Index Copernicus Value (2015): 78.96 | Impact Factor (2015): 6.391

\begin{tabular}{|c|c|c|c|c|c|c|}
\hline 11 & Availability of cold storage at distance & $61(38.12)$ & $33(20.60)$ & $66(41.25)$ & 01.96 & $\mathrm{X}$ \\
\hline 12 & Lack of potato processing unit & $81(50.62)$ & $56(35.00)$ & $23(14.38)$ & 02.36 & III \\
\hline 13 & Lack of marketing facilities through corporative societies & $67(41.87)$ & $23(14.37)$ & $70(43.75)$ & 01.98 & IX \\
\hline 14 & Fluctuation of price & $90(56.25)$ & $52(32.50)$ & $18(11.25)$ & 02.45 & I \\
\hline 15 & Lock of marketing information & $61(38.12)$ & $46(28.75)$ & $53(33.12)$ & 02.05 & VIII \\
\hline 16 & Lack of information regarding need & $75(46.87)$ & $64(40.00)$ & $21(13.12)$ & 02.33 & IV \\
\hline 17 & Lack of awareness regarding market price of potato & $46(28.75)$ & $38(23.75)$ & $76(47.50)$ & 01.81 & XIII \\
\hline
\end{tabular}

Data pertinent to constrains faced in potato cultivation is presented in table 01 revealed that majority about forty per cent and little more $(40.62 \%)$ respondents were ,Sometimes ${ }^{\text {ee }}$ and „Always "e facing problem of „Unavailability of labour"e, while about nineteen per cent respondents ,Never" faced this problem with Mean Score 2.21, Rank VI. Maximum (43.75\%) respondents ,Sometimes ${ }^{\text {ee }}$ faced „High cost of input for potato cultivation "e as a constraint followed by 35.00 per cent respondents „Nevere faced the problem of high cost. About twenty one per cent (Mean Score 1.86, Rank XII) respondents „Always ${ }^{\text {ee }}$ found the problem of „High cost of input for potato cultivation ${ }^{e e}$.

„Shortage of labour during season ${ }^{e e}$ was „Alwayse and „Nevere felt by 42.50 per cent respondents respectively, whereas 8.12 per cent ,Sometimes ${ }^{\text {ee }}$ faced this problem (Mean Score 2.06, Rank VII). „Untimely wage payment ${ }^{\text {ec }}$ was ,Nevere a problem for 53.75 per cent respondents but 32.50 per cent respondents ,Sometimes "e faced the problem of „Untimely wage payment”. About fourteen per cent respondents „Always ${ }^{\text {ee }}$ faced problem of „Untimely wage payment" (Mean Score 1.66, Rank XIV). About fifty six per cent respondents ,Never ${ }^{\text {ee }}$ found the problem of ,No employment in odd season "e followed by 38.75 per cent respondents ,Sometimes ${ }^{\text {ee }}$ faced this problem. Only five per cent respondents „Always"e faced the problem of „No employment in odd season “e ,Availability of sufficient good quality seed ${ }^{\text {ee }}$ one of the constraints was ,always "e faced by 56.87 per cent respondents but in contrast, about thirty one per cent respondents 'Never' faced while 12.50 per cent respondents ,Sometimes"e faced this constraint (Mean Score 2.26, Rank V). An equal percentage (38.12\%) respondents were „Alwayse and ,Sometimese faced the problem of „Enough fertilizer not available in time e, whereas 23.75 per cent respondents „Never" faced (Mean score 2.14, RankVII). More than thirty five per cent respondents ,Never faced problem of ,Low cost transport system ${ }^{\text {ee }}$ while about thirty eight per cent respondents ,Sometimese faced but more than one quarter respondents "Always"e suffered the problem of low cost system (Mean Score 1.89, Rank XI). A little less than fifty per cent respondent's ,Always ${ }^{\text {ee }}$ faced problem of „High charges of cold storage ee followed by 28.12 per cent respondents ,Nevere faced, whereas 22.50 per cent reported that ,Sometimese they were unable to use the cold storage facility because of high charges (Mean Score 2.21, Rank VI). Majority (48.75\%) of respondents ,Sometimes ${ }^{\text {ee }}$ faced „Unavailability of cold storage constraint, whereas little less i.e. 44.37 per cent respondents faced „Always"e. Only about seven per cent respondents „Never"e faced the problem of „Unavailability of cold storagee identified Rank II with Mean Score 2.37.
About forty one per cent respondents ,Nevere faced the constraint of ,Availability of cold storage at distance from field and market ${ }^{\text {e }}$ but in contrast 38.12 per cent respondents „Always "e faced while 20.60 per cent reported ,Sometimes (Mean Score 1.96, Rank X). More than fifty per cent respondents ,Alwayse faced problem of lack of potato processing unit followed by 35.00 per cent respondents ,Sometimese, whereas about fourteen per cent respondents „Never"e reported the problem of non-availability of potato processing unit as Rank III with Mean Score 2.36. „Lack of marketinge facilities through co-operatives constraint was „Always "e and „Never"e faced by about forty four and forty two per cent respondents respectively while 14.37 per cent respondents „Sometimese faced (Mean Score 1.98, Rank IX). Maximum about fifty six per cent respondents ,Always ${ }^{\text {ee }}$ faced problems of ,Fluctuation of price ee followed by 32.50 per cent respondents ,Sometimes ${ }^{\text {ee }}$, whereas about eleven per cent respondents „Never ${ }^{\text {ee }}$ faced this problem thus identified Rank I, with Mean Score 2.45. About-thirty eight per cent respondents „Alwayse faced „Lack of marketing informatione $^{\text {ee }}$ as a constraint followed by 33.12 per cent respondents „Never" faced this problem (Table 4.16). About twenty nine per cent respondents ,Sometimes ${ }^{\text {ee }}$ faced problem of „Lack of marketing information "e with Mean Score 2.05 and Rank VIII. About forty seven per cent respondents ,Always ${ }^{\text {ee }}$ faced „Lack of information "e regarding need followed by forty per cent respondents faced ,Sometimese but in contrast, about thirteen per cent respondents reported „Nevere (Mean score 2.33, Rank IV) faced the problem of lack of information regarding potato cultivation practices. Maximum (47.50\%) respondents

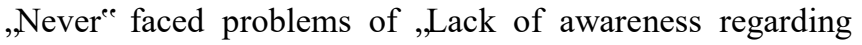
market price of potato "e while about twenty nine per cent reported „Always"e, whereas 23.75 per cent respondents faced ,Sometimese the problem of lack of awareness regarding market price of potato (Mean Score 1.81, Rank XIII).

\section{Conclusion}

Potato is the main source of important nutrient but the productivity and processing has not been able to keep pace with the current trends because potato growers are facing constraints while performing farm field activities. As per table 01, that more than fifty percent respondents ,Always ${ }^{\text {ee }}$ suffered with problem of ,fluctuation of price ${ }^{e e}$ and, therefore, this constraint was identified as Rank I. Major constraints „Always "e faced by maximum respondents were „Unavailability of cold storage and „lack of potato processing unite and thus identified Rank II and Rank III. Untimely "wage payment" and "no employment in odd season" were identified least faced constraints with Rank XIV and Rank XV respectively. 


\section{References}

[1] Prakash, V. (2007) Impact of socio-economic profile on potato growers. Internat. J. Plant Sci. 2(1): 247-250.

[2] Scott, G.J. and Suarez, V. (2011) Growth rates for potato in India and their implications for industry. Potato $J$.38 (2): 100-112.

[3] Thompson, H.C. and Kelly, W.C. (1957) Vegetable Crops. New York. Mc Grow-Hill Book Company Inc. 